\title{
Evaluation of insecticides against blister beetle (Mylabris pustulata Thunb.) on pigeonpea, Cajanus cajan
}

\author{
Krishna Rolania*, S. S. Yadav and R. K. Saini \\ Department of Entomology, Chaudhary Charan Singh Haryana Agicultural University, Hisar (Haryana), INDIA \\ *Corresponding author. Email: krish81rolania@rediffmail.com \\ Received: November 24, 2014; Revised received: November 26, 2015; Accepted: January 28, 2016
}

\begin{abstract}
Blister beetle, Mylabris pustulata (Family: Meloidae: Coleoptera) an important pest of pigeonpea, Cajanus cajan when fed on its different floral parts including petals, anthers, stigma and ovary. Stigma and ovary were damaged and there was no pod formation. In view of its significant damage potential, a few number of insecticides were evaluated against the beetles in the laboratory: thiodicarb $(0.09 \%)$, chlorpyriphos $(0.10 \%)$, quinalphos $(0.10 \%)$, cypermethrin $(0.007 \%)$, deltamethrin $(0.012 \%)$ and novaluron $(0.10 \%)$. Fresh pigeonpea twigs bearing flowers were dipped for 5 seconds in requisite concentrations of different insecticides and allowed to air dry at room temperature $\left(28^{\circ} \mathrm{C}\right)$. For each treatment, three replicates were taken and dead beetle were counted 24 and 48 hours after release. Observations after 24 hours of application indicated that thiodicarb (84.23\%), chlorpyriphos (57.50 \%), quinalphos $(37.31 \%)$ and cypermethrin $(29.77 \%)$ significantly reduced blister beetle population compared with the control (without insecticidal treatment). After 48 hours, all insecticidal treatments were significantly superior over control. Maximum cumulative mortality (100\%) was observed in thiodicarb followed by quinalphos $(95.7 \%)$, cypermethrin $(95.7 \%)$ and chlorpyriphos $(91.6 \%)$, while minimum in novaluron and deltamethrin. It was concluded from the studies that among the different insecticidal treatments thiodicarb $(0.09 \%)$ proved most effective which brought $99.75 \%$ mortality even 24 hours after the treatment.
\end{abstract}

Keywords: Blister beetle, Mylabris pustulata, Pigeonpea, Preferred host

\section{INTRODUCTION}

Pigeonpea is an important legume crop of rainfed agriculture in the semiarid tropics. Apart from being attacked by some regular insect pests like pod borer and tur pod borer, it was observed to be damaged by blister beetle, Mylabris pustulata; at the research farm during kharif 2011. It is a polyphagous pest attacking various pulses, malvaceous and cucurbitaceous crops. Though pigeonpea is the most preferred host for development and survival of this pest (Balikai, 2000 and Durairaj, 2000) yet this pest could inflict considerable damage to this crop, particularly if its attack started at early flowering stage. Adult beetles feed on different floral parts including petals, anthers, stigma and ovary. Sometimes, ovary is completely eaten away resulted no pod formation. The pest has direct impact by damaging the foliage and feeding on crops or indirect by suppressing the population of pollinators (Ghoneim, 2013). Very little work has been done on control of blister beetle (Badiyala, 2011 It has been observed that the adults of M. Pustulata cause severe damage to pigeonpea by eating the buds and flowers wholly or partially (Mann and Dhooria, 1993 and Dhakla, et al. 2010). Therefore, keeping in view, the severity of damage caused by this pest, efforts were made to evaluate some new insecticides against $M$. Pustulata.

\section{MATERIALS AND METHODS}

A pigeonpea (Variety: Paras) was sown at the research farm of the Department of Entomology CCS HAU, Hisar during June, 2011. Recommended package of practices was followed to raise the crop (Anonymous, 2013). When the pest appeared on the crop, the adult beetles were exposed to different concentrations of the insecticides. These were; thiodicarb $(0.09 \%)$, chlorpyriphos $(0.10 \%)$, quinalphos $(0.10 \%)$, cypermethrin $(0.007 \%)$, deltamethrin $(0.012 \%)$ and novaluron $(0.10 \%)$. In all, there were seven treatments including control with three replications for each. Fresh pigeonpea twigs bearing flowers were plucked from the plants and brought to the laboratory. These were dipped for 5 seconds in requisite concentrations of different insecticides, spread over filter paper and allowed to air dry at room temperature $\left(28^{\circ} \mathrm{C}\right)$. For each treatment three such twigs were placed in a glass jar $(15 \times 20$ c. m.) and a batch of 8 beetles per jar was released. The open end of the jars was covered with muslin cloth fastened with elastic bands. Observations on number of dead and living beetles were made after 24 and 48 hours of release. The data were transformed using angular transformation and subjected to analysis of variance using Completely Randomized Design (CRD). 
Table1. Effect of different insecticides on population of M. pustulata adults.

\begin{tabular}{lccc}
\hline Treatment & $\begin{array}{c}\text { Concentration } \\
(\%)\end{array}$ & \multicolumn{2}{c}{ Mean \% of dead beetles (hours after exposure) } \\
\cline { 3 - 4 } & 0.09 & $100(87.10)$ & $\mathbf{4 8}$ hrs (cumulative mortality) \\
\hline Thiodicarb (Larvin 75 WP) & 0.10 & $75(60.37)$ & $100(87.10)$ \\
Chlorpyriphos (Dursban 20 EC) & 0.10 & $41.62(40.18)$ & $91.62(78.06)$ \\
Quinalphos (Flash 25 EC) & 0.007 & $29.12(32.64)$ & $95.75(81.16)$ \\
Cypermethrin (Super Fighter 25 EC) & 0.012 & $8.25(16.81)$ & $62.37(52.26)$ \\
Deltamethrin (Decis 10 EC) & 0.01 & $8.25(16.86)$ & $62.37(52.39)$ \\
Novaluron (Rimon 10 EC) & -- & $0.00(2.87)$ & $0.00(2.87)$ \\
Control & -- & 5.90 & 15.37 \\
CD p=0.05 & - &
\end{tabular}

Sample size: 8 beetle/replicate; Design: CRD; Replicates: 3; Figures in parentheses are angular transformations

\section{RESULTS AND DISCUSSION}

The data on mortality of adult blister beetle due to application of different insecticides are presented in Table 1. Observations after 24 hours of treatment indicated that thiodicarb, chlorpyriphos, quinalphos and cypermethrin significantly $(84.23,57.50,37.31$ and $29.77 \%$ respectively) reduced blister beetle population over the control. At this observation interval, all beetles were found dead in thiodicarb $0.09 \%$ which differ significantly (16.73\%) from that of chlorpyriphos $0.10 \%$. Second highest mortality of beetles was observed in chlorpyriphos $0.10 \%$ which was significantly higher than quinalphos $0.10 \%$. The remaining treatments gave poor mortality of the beetles, with minimum mortality in novaluron and deltamethrin. These findings were strengthened by the laboratory bioassay data of Shende et al., 2013 who reported that chlorpyriphos $50 \mathrm{EC}+$ cypermethrin $5 \mathrm{EC}(0.1375 \%)$, cypermethrin 10 EC $(0.01 \%)$, fenvalerate 20 EC $(0.02 \%)$ at field dose inflicted 100 per cent mortality, within 24 hours.

Observations after 48 hours indicated that all insecticidal treatments were significantly $(84.23,75.19$, $78.29,92.88,49.37$ and $49.52 \%$ ) superior over control. Maximum cumulative mortality $(100 \%)$ was observed in thiodicarb followed by quinalphos $(95.7 \%)$, cypermethrin (95.7\%) and chlorpyriphos (91.6\%), while minimum in novaluron and deltamethrin. These finding are strengthened by Dhavan, et al., 2014 reported that application of cypermethrin $10 \mathrm{EC}(1 \mathrm{ml} / \mathrm{L})$, chlorpyriphos $20 \mathrm{EC}(2 \mathrm{ml} / \mathrm{L})$, and acephate $75 \mathrm{SP}(2$ $\mathrm{g} / \mathrm{L})$ were more effective in minimizing adult blister beetles abundance on greengram at flowering phase. Pawar et al., 2013 in his study on evaluation of insecticides for the management of blister beetles inferred that the application of cypermethrin 10 EC @ 0.01 per cent, chlorpyriphos $50 \mathrm{EC}+$ cypermethrin 5 EC @ 0.1375 per cent and lambda cyhalothrin 2.5 EC @ 0.00375 per cent were most effective insecticides in minimizing the adult blister beetles abundance on greengram. Lal and Jat (2014) revealed that decamethrin 2.8 EC and thiodicarb $75 \mathrm{WP}$ caused cent per cent mortality of adult blister beetle immediately after treatment spray. Present findings are supported with the results of Durairaj and Ganapathy (1999) who reported that $M$. pustulata was susceptible to fenvalerate and cypermethrin. These findings are slightly supported with the results of Sharma (1994), Kakar and Dogra (1988) and Ram et al. (1988) suggesting effective control of this pest with monocrotophos, fenvalerate, cypermethrin and decamethrin.

\section{Conclusion}

It can be inferred from the findings of the present study that effective management of adult blister beetles was obtained by thiodicarb $(0.09 \%)$ with cent per cent mortality even after 24 hours. Application of quinalphos $(0.10 \%)$ and cypermethrin $(0.007 \%)$ stood second in obtaining mortality of adult blister beetle. The present finding can be utilized by targating the adult blister beetles in their most favoured crop phenology, the flowering phase to ensure the cost effectiveness of the treatments.

\section{REFERENCES}

Anonymous (2013). Package of practices, College of Agriculture Choudhary Charan Singh Haryana Agricultural University, Hisar.

Badiyala, A. (2011). Seasonal incidence of blister beetles (Mylabris spp.) on okra in Himachal Pradesh. Journal of Hill Agricuture, 2 (2): 183-188.

Balikai, R.A. (2000). Incidence of blister beetle, Mylabris pustulata (Thunberg) on different host plants. Insect Environment, 6 (1): 12.

Dhakla, K., Yadav, G. S. And Rohilla, H. R. (2010). Incidence and flower damage of pigeonpea genotypes by blister beetle, Mylabris Pustulata Thunberg, 23 (3): 348 -350 .

Durairaj, C. (2000). A note on the host preference by two species of blister beetle in pulse crops. Madras Agricultural Journal, 87 (4/6): 355-356.

Durairaj, C. and Ganapathy, N. (1999). Toxicity of nine insecticides to three species of blister beetle (Mylabris spp.) in pigeonpea (Cajanus cajan). Indian Journal of Agricultural Sciences, 69 (6): 468-469.

Ghoneim, K. (2013). Agronomic and biodiversity impacts of the blister beetles (Coleoptera: Meloidae) in the world: A review. International Journal of Agricultural Science Research, 2 (2): 21-36.

Kakar, K. L. and Dogra, G. S. (1988). Insect-pest of okra, Abelmoschus esculentus (L.) Moench and their control 
under mid-hill conditions. Journal of Insect Sciences, 1 (2): 195-198

Lal, R. and Jat, B. 2014. Bioefficacy and persistency of insecticides against blister beetle, Mylabris pustulata (Thunb.) in pigeonpea (Cajanus cajan (L.) Millsp.) . International Conference: Changing Scenario of Pest Problems in Agri-horti Ecosystem and their Management, 27-29 November organized by Entomological Research Association, Department of Entomology, Rajasthan College of Agriculture, MPUAT, Udaipur, 1314.

Mann, G. S. And Dhooria, M. S. (1993). Feeding and mating behaviour of blister beetle on pigeonpea. International Pigeonpea Newsletter, 17: 40-42.

Pawar, K. S., Shende, S. P., Wadaskar, R. M. and Thakare,
A. Y. 2013. Studies on insecticide efficacy and application schedule for management of blister beetles on greengram. Journal of Food Legumes, 26 (3 \& 4): 6369.

Ram, S., Gupta, M. P. and Maurya, R. P. (1988). Efficacy of three insecticides applied in three regimes against insect pests of cowpea. Indian Journal of Plant Protection, 16 (1): $17-20$.

Sharma, S. S. (1994). Insecticidal control of Mylabris pustulata. Haryana Journal of Horticultural Sciences, 23(4): 96.

Shende, Sarika, Thakare, A. Y. and Wadaskar, R. M. (2013). Dose mortality responses of blister beetles against some insecticides. The Bioscan. 8 (3): 1061-1064 (Supplement of Toxicology). 